\title{
Manufacture LIMS
}

National Cancer Institute

\section{Source}

National Cancer Institute. Manufacture LIMS. NCI Thesaurus. Code C44470.

Information on the physical production of arrays within the laboratory. (caMAGE) 